\title{
Successful outcome following pneumonectomy in a teenage boy with cystic fibrosis: a case report
}

\author{
Zheyi Liew', Santosh Mallikarjuna', Asif Hasan², F. Kate Gould³ , Su Bunn ${ }^{4}$, Matthew F. Thomas', Jim L. Lordan³, \\ Christopher $\mathrm{O}^{\prime}$ Brien $^{1}$ and Malcolm Brodlie ${ }^{5^{*}}$ (D)
}

\begin{abstract}
Background: Cystic fibrosis lung disease is generally a diffuse process however rarely one lung may become particularly damaged through chronic collapse and consolidation resulting in end-stage bronchiectasis with relative sparing of the contralateral lung. This clinical situation is sometimes referred to as "destroyed lung". Lung resection surgery is seldom indicated in cystic fibrosis and the associated medical literature is relatively sparse.

Case presentation: A 14 year old boy was referred to our centre for lung transplantation assessment. He had a chronic history of complete collapse and consolidation of his entire right lung. This was causing severe morbidity in terms of a continuous requirement for intravenous antibiotics over the last year, poor exercise tolerance with forced expiratory volume in $1 \mathrm{~s}$ of $35-40 \%$ predicted and need for home tuition. He also had significant nutritional problems and gastrointestinal symptoms following a Nissen's fundoplication operation a year earlier. His nutritional status was firstly improved by the institution of jejunal feeding, which also greatly improved his distressing symptoms of nausea and wretching. After thorough multidisciplinary assessment the therapeutic option of performing a right pneumonectomy was considered due to relative sparing of the left lung, which demonstrated only mild bronchiectasis on computed tomography scan. This was performed uneventfully with a smooth peri-operative course. Targeted antimicrobials were used to treat the multiresistant organisms colonising his airways. Subsequently his quality of life, nutritional status and lung function all improved significantly and requirement for lung transplantation has been delayed.
\end{abstract}

Conclusions: We report a successful outcome following pneumonectomy in a teenage boy with cystic fibrosis referred to our centre for lung transplantation assessment with chronic unilateral collapse and consolidation of his right lung. We believe that improvement of nutritional status pre-operatively and targeted antimicrobial therapy, all contributed to the smooth peri-operative course. Pneumonectomy can be a feasible option in this clinical situation in cystic fibrosis but the associated risks must be considered carefully on a case-by-case basis.

Keywords: Cystic fibrosis, Pneumonectomy, Destroyed lung, Paediatrics, Case report

\section{Background}

Cystic fibrosis (CF) is the most common genetically acquired life-limiting disorder in populations of European ancestry. Lung disease is responsible for the vast majority of morbidity and mortality in people with CF [1]. Lung transplantation is the only therapeutic option for end-stage

\footnotetext{
* Correspondence: malcolm.brodlie@ncl.ac.uk

${ }^{5}$ Institute of Cellular Medicine, Newcastle University and Department of Paediatric Respiratory Medicine, Great North Children's Hospital, Level 3 Clinical Resource Building, Royal Victoria Infirmary, Queen Victoria Road, Newcastle upon Tyne NE1 4LP, UK

Full list of author information is available at the end of the article
}

disease but is itself associated with morbidity and limited survival. CF lung disease is characterised by progressive neutrophilic airway inflamation, retention of mucopurulent secretions and endobronchial infection with specific microbes, most notably Pseudomonas aeruginosa [2].

CF lung disease is generally diffuse and bilateral although inhomogeneity is recognised between different lobes and rarely disease may become markedly severe in specific lobes or in one lung [3, 4]. If a collapsed/consolidated lung is not reinflated then a vicious cycle of mucus impaction, infection and inflammation can lead 
to irreversible damage $[5,6]$. In extreme cases a phenomenon known as 'destroyed lung' may occur where an entire lung is irreversibly damaged, contributing little to ventilation yet causing significant problems with chronic infection [6]. Potentially life-threatening complications may occur including septicaemia, haemoptysis, empyema, pulmonary-systemic shunting and pulmonary hypertension [5, 6]. Surgical pneumonectomy to remove the destroyed lung may be indicated but is not without associated risks and importantly is only a viable option if the contralateral lung is not severely involved. On occasions one specific lobe may be causing severe problems and consideration may be given to the pros and cons of lobectomy in such cases $[7,8]$.

Published literature on lung resection in children with 'destroyed lung' in general is relatively limited with even fewer examples in children specifically with CF. In 2003, Eren et al. reported the results of surgery in a series of 17 children undergoing pneumonectomy for 'destroyed lung' secondary to suppurative or necrotic lung disease, but not CF [5]. In this series two children died in the peri-operative period and four developed post-operative complications including empyema, haemorrhage requiring re-thoracotomy and broncho-pleural fistula. Longerterm follow up suggested that the majority of surviving children had increased exercise tolerance [5]. In 2010 Kosar et al. reported comparatively improved outcomes in a non-CF case series of 18 children who underwent pneumonectomy for 'destroyed lung' [6]. Pre-operative ventilation-perfusion scans demonstrated that contribution from affected lungs was minimal. In this series there was no peri-operative mortality and a complication rate of $17 \%$ including a wound infection and bronchopleural fistula and empyema. The authors concluded that favourable outcomes were due to case selection, optimisation of nutritional status, use of targeted antimicrobials and pro-active physiotherapy post-operatively [6]. Smith et al. also reported their experience of nine paediatric and four adult patients with CF who underwent a total of 17 major lung resections over a decade in the 1980's [9]. Three pneumonectomies were performed in children. Overall in $75 \%$ of the pneumonectomy patients there was a decrease in symptoms, increased sense of well-being, and reduction in admission rates postoperatively [9].

In this paper we report a successful outcome following pneumonectomy in a teenager with a 'destroyed' right lung referred to our centre for lung transplantation assessment.

\section{Case presentation}

A 14-year-old boy with CF (CFTR genotype Phe508del/ Phe508del) was referred for lung transplant assessment. $\mathrm{He}$ was diagnosed with $\mathrm{CF}$ as a 3 month old infant having presented with recurrent pneumonia and malabsorption. His forced expiratory volume in $1 \mathrm{~s}\left(\mathrm{FEV}_{1}\right)$ was $0.8 \mathrm{~L}$ (39\% predicted) and there was a severe problem with collapse and consolidation of his entire right lung (Fig. 1). He completed $395 \mathrm{~m}$ with lowest oxygen saturations of $92 \%$ during a 6 min walk test in room air. His lung function had progressively reduced over the previous 4 years with chronic collapse of the right lung evident on chest radiographs for the last 2 years. He was experiencing significant morbidity in association with these problems including a continuous requirement for intravenous antibiotics over the preceding 12 months, limited exercise tolerance necessitating home tuition and overall poor quality of life. As a consequence his left lung was hyper-expanded but notably had only mild bronchiectasis on a recent high-resolution computed tomography scan (Fig. 2). Pan-resistant Pseudomonas aeruginosa and Stenotrophomonas maltophilia were commonly isolated from his sputum along with Aspergillus terreus. Nontuberculous mycobacteria nor Mycobacterium tuberculosis had ever been cultured from respiratory samples.

The boy also had substantial gastrointestinal and nutritional problems. He had undergone a Nissen's fundoplication around a year previously at his home centre to try and improve problems with gastro-oesophageal reflux. However he had continued to experience distressing symptoms of nausea, retching and vomiting, particularly in association with gastrostomy feeds, that limited his nutritional intake post-fundoplication. At referral his weight at $26.6 \mathrm{~kg}$ and height at $1.39 \mathrm{~m}$, were both significantly below the 0.4 th centiles for his age.

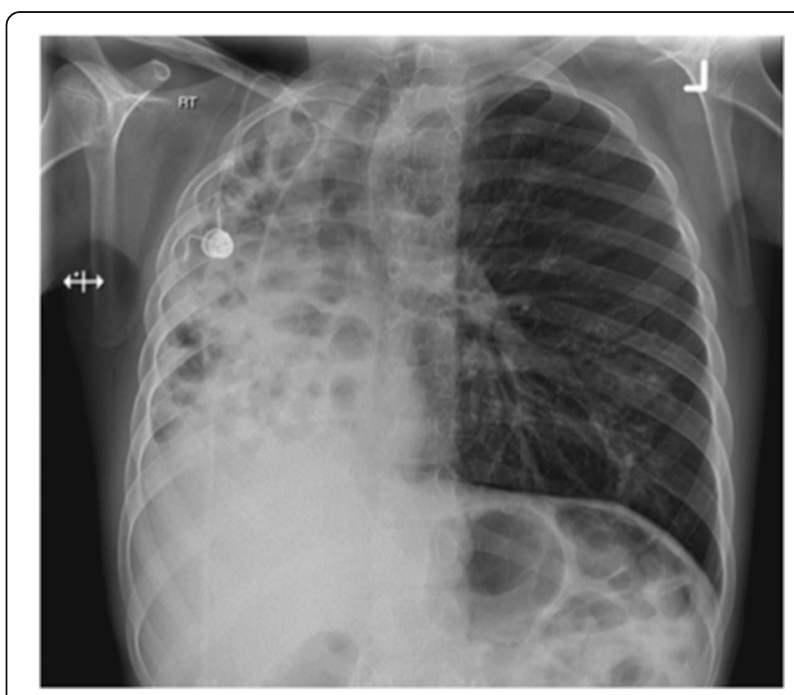

Fig. 1 Pre-operative chest radiograph at time of initial assessment showing presence of severe right lung collapse and consolidation leading to mediastinal shift to the right with hyperexpansion of the left lung 


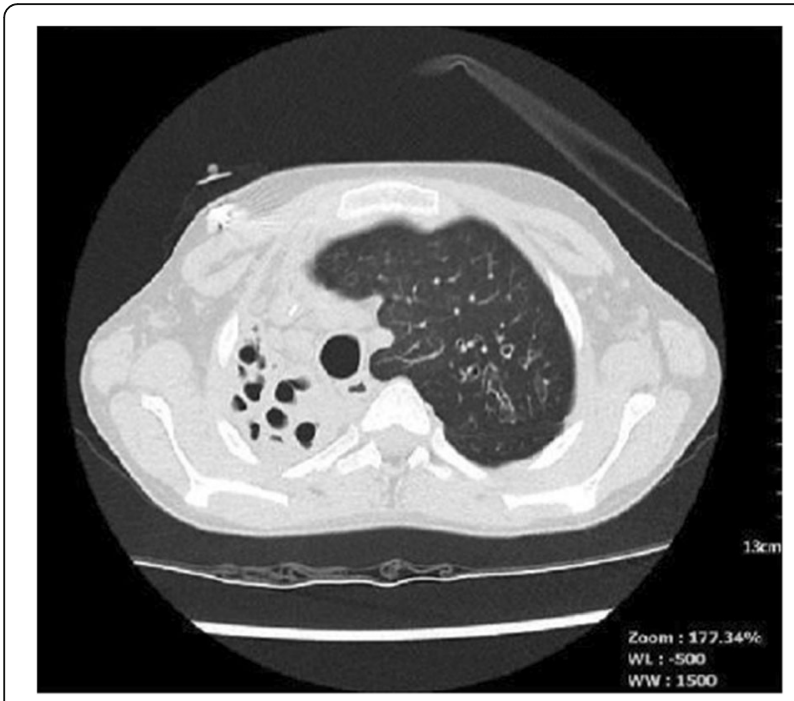

Fig. 2 Pre-operative chest high-resolution computed tomography scan showing severe bronchiectasis of the right lung and hyperexpansion of the left lung with mediastinal shift to the right, but relatively minor bronchectasis

An inpatient assessment was arranged in our centre during which a trial of stopping intravenous antibiotics led to rapid signs of sepsis. His debilitating gastrointestinal problems were also clearly evident and he was also reviewed by a Consultant Paediatric Gastroenterologist. His abdominal symptoms were felt to be suggestive of gastroparesis or delayed gastric emptying and visceral hypersensitivity. He was started on gabapentin for visceral hypersensitivity and plans were made for a further admission for a trial of jejunal feeding using an amino acid feed to further manage symptoms and improve nutritional status.

In parallel careful multidisciplinary discussions were held and although relatively high risk it was felt that a right pneumonectomy could be a beneficial intervention to remove a chronic sump of infection and improve his current status as a strategy to delay the need for active listing for lung transplantation. It was confirmed that implantation of a single donor lung, rather than bilateral lung transplantation, was the only viable option at any stage in his case due to chronic remodelling that had occurred of the right hemithorax with markedly reduced volume compared to the left. This was discussed fully with the patient and his family and a plan was agreed to improve his nutrition as far as possible prior to performing a pneumonectomy.

He was subsequently re-admitted and a jejunal extension was added to his gastrostomy and a flexible bronchosocopy performed. The bronchoscopy revealed normal left-sided bronchial anatomy and on the right a tracheal bronchus with mucoid plugs obstructing all major bronchi. Bronchoalveolar lavage fluid grew S. maltophilia, A.
Terreus and Staphylococcus aureus. Continuous jejunal feeding (Elemental E208, Nutricia) was introduced and led to a rapid gastrointestinal symptomatic improvement with much less retching and vomiting.

Following three weeks of jejunal feeding, during which time he gained $2.4 \mathrm{~kg}$, the pneumonectomy was performed. The operation was surgically uneventful, he was extubated within $24 \mathrm{~h}$ and was discharged from intensive care to the ward on the first post-operative day. Amikacin, piperacillin/tazobactam, moxifloxacin and posaconazole were used to provide targeted antimicrobial cover. His subsequent course was smooth with rapid improvement in chest symptoms and successful withdrawal of intravenous antibiotics. His gastrointestinal symptoms also continued to improve and he gained a further $1 \mathrm{~kg}$ prior to discharge home three weeks later.

In the 2 years following surgery he has been followed up by his local centre. There has been a dramatic improvement in quality of life, evidenced by good school attendance, physical activity and that he has only required admission to hospital for one course of intravenous antibiotics. Importantly his lung function has increased substantially to around $65-70 \%$ predicted $\mathrm{FEV}_{1}$ and he has gained a further $5 \mathrm{~kg}$ in weight with now both height and weight following the same centile. Figure 3 shows a chest radiograph around 6 months post-pneumonectomy.

\section{Conclusions}

We report a successful outcome following pneumonectomy in a teenage boy with CF and 'destroyed' right lung as a strategy to improve his clinical status and quality of life to an extent that it has delayed requirement for

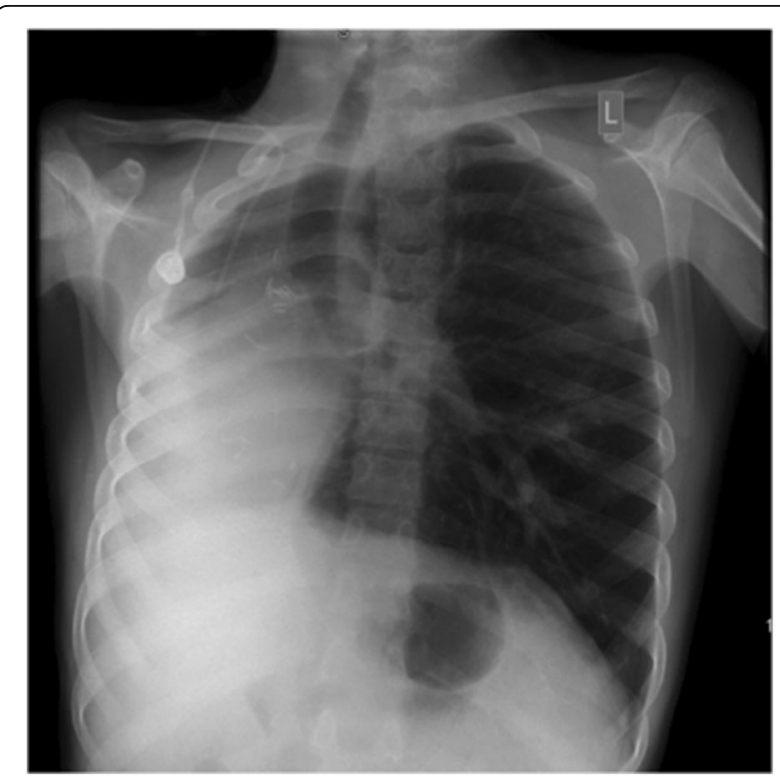

Fig. 3 Chest radiograph around 6 months post-pneumonectomy 
active lung transplantation listing. Pneumonectomy is not without associated risks and is an uncommon procedure in CF as it is generally a diffuse lung disease. This case demonstrates however that it can be a feasible option in this extreme clinical situation.

We believe that careful case selection, improvement of nutritional status pre-operatively and targeted antimicrobial therapy all contributed to the smooth peri-operative course and successful outcome. All of these factors must be balanced against the risks of surgery and pneumonectomy should only be considered in patients with severe unilateral problems. Furthermore, post-pneumonectomy children may develop problems with scoliosis that may be severe and associated with respiratory problems. In general optimal timing of surgery with regard to the pubertal growth spurt and consideration of the use of prophylactic tissue expanders may reduce the likelihood of these issues however [10].

This intervention has improved the patient's quality of life considerably - both lung function and weight have increased substantially. It should be noted that in the context of a previous contralateral pneumonectomy future single lung transplantation may be technically more challenging but ultimately has been associated with good outcomes [11, 12].

The boy in this case experienced significant gastrointestinal symptoms, in the form of gastroesophageal reflux disease pre-fundoplication, and severe problems post-fundoplication likely secondary to gastrointestinal dysmotility. The exact relationship between gastroesophageal reflux and aspiration of refluxate in CF lung disease is unclear but there is potential for this to contribute to airway injury and reflux-induced cough and reported symptoms have been associated with reduced lung function in adults [13-15]. It is uncertain as to how he developed such severe problems in the right lung but it is possible to speculate that recurrent reflux/aspiration may have played some role prefundoplication. In addition the presence of a tracheal bronchus was of uncertain contribution to the development of his problems on the right side. Histology of the resected lung showed severe bronchiectasis throughout all lobes with a dense inflammatory infiltrate of neutrophils and lymphocytes. In general we would recommend a proactive approach in any child or young person with CF that develops lobar collapse and consolidation. This is likely to involve bronchoscopic clearance of mucus and secretions, targeted antimicrobials, mucolytics and intensive physiotherapy in order to try and avoid more chronic problems developing and irreversible lung damage.

Abbreviations

CF: Cystic fibrosis; FEV 1 : Forced expiratory volume in $1 \mathrm{~s}$

\section{Acknowledgements}

We gratefully acknowledge the support and hard work of the wider CF multidisciplinary team at the Great North Children's Hospital and staff at the Freeman Hospital, Newcastle upon Tyne Hospitals NHS Foundation Trust.

\section{Funding}

MB is supported by the Medical Research Council (Clinician Scientist Fellowship, MR/M008797/1) and the CF Trust (SRC 003). There was no involvement in the writing of the manucript by the funding bodies.

\section{Availability of data and materials}

Not applicable.

\section{Authors' contributions}

ZL and SM: Prepared the first draft of the manuscript. AH, FKG, SB, MFT and COB: Commented on the drafts. MB: Completed the final version.

\section{Authors' information}

ZL and SM are Registrars in Paediatric Respiratory Medicine who were involved in the management of the case. AH is a Consultant Cardiothoracic Surgeon who performed the operation. FKG is a Consultant Microbiologist who advised on use of antimicrobials. SB is a Consultant Paediatric Gastroenterologist who led on the gastrointestinal and nutriton management. MB, MFT and COB are Consultants in Paediatric Respiratory Medicine who were involved in the management of the case.

\section{Competing interests}

The authors declare that they have no competing interests.

\section{Consent for publication}

Permission has been granted for publication of this case from the patient's parents, a signed consent form is available to the Editors on request.

\section{Ethics approval and consent to participate}

See consent for publication below.

\section{Author details}

'Department of Paediatric Respiratory Medicine, Great North Children's Hospital, Newcastle upon Tyne, UK. ${ }^{2}$ Department of Paediatric Cardiothoracic Surgery, Freeman Hospital, Newcastle upon Tyne, UK. ${ }^{3}$ Institute of Transplantation, Freeman Hospital, Newcastle upon Tyne, UK. ${ }^{4}$ Department of Paediatric Gastroenterology, Great North Children's Hospital, Newcastle upon Tyne, UK. Institute of Cellular Medicine, Newcastle University and Department of Paediatric Respiratory Medicine, Great North Children's Hospital, Level 3 Clinical Resource Building, Royal Victoria Infirmary, Queen Victoria Road, Newcastle upon Tyne NE1 4LP, UK.

Received: 27 September 2016 Accepted: 12 December 2016 Published online: 13 January 2017

\section{References}

1. Ratjen F, Bell SC, Rowe SM, Goss CH, Quittner AL, Bush A. Cystic fibrosis. Nat Rev Dis Primers. 2015;1 (1):1-19.

2. Haq IJ, Gray MA, Garnett JP, Ward C, Brodlie M. Airway surface liquid homeostasis in cystic fibrosis: pathophysiology and therapeutic targets. Thorax. 2016;71(3):284-7.

3. Meyer KC, Sharma A. Regional variability of lung inflammation in cystic fibrosis. Am J Respir Crit Care Med. 1997;17(2):1536-40.

4. Gilchrist FJ, Salamat S, Clayton S, Peach J, Alexander J, Lenney W. Bronchoalveolar lavage in children with cystic fibrosis: how many lobes should be sampled? Arch Dis Child. 2011;96:215-7.

5. Eren S, Eren MN, Balci AE. Pneumonectomy in children for destroyed lung and the long-term consequences. J Thorac Cardiovasc Surg. 2003;126(2): 574-81.

6. Kosar A, Orki A, Kiral H, Demirhan R, Arman B. Pneumonectomy in children for destroyed lung: evaluation of 18 cases. Ann Thorac Surg. 2010;89(1):226-31.

7. Lucas JSA, Connett GJ, Fairhurst J. Long term results of lung resection in cystic fibrosis patients with localised lung disease. Arch Dis Child. 2002;86:66.

8. Lucas J, Connet GJ, Lea R, Rolles CJ, Warner JO. Lung resection in cystic fibrosis patients with localised pulmonary disease. Arch Dis Child. 1996;74:449-51. 
9. Smith MB, Hardin Jr WD, Dressel DA, Beckerman RC, Moynihan PC. Predicting outcome following pulmonary resection in cystic fibrosis patients. J Pediatr Surg. 1991;26(6):655-9.

10. Choi L, LaQuaglia MP, Cordeiro PG. Prevention of postpneumonectomy syndrome in children with prophylactic tissue expander insertion. J Pediatr Surg. 2012;47(7):1354-7.

11. Le Pimpec-Barthes F, Thomas PA, Bonnette P, Mussot $S$, Defrancquen $P$, Hernigou A, Latremouille C, Riquet M. Single-lung transplantation in patients with previous contralateral pneumonectomy: technical aspects and results. Eur J Cardiothorac Surg. 2009;36(5):927-32.

12. Forty J, Hasan A, Gould FK, Corris PA, Dark JH. Single lung transplantation with simultaneous contralateral pneumonectomy for cystic fibrosis. J Heart Lung Transplant. 1994;13(4):727-30.

13. McNally P, Ervine E, Shields MD, Dimitrov BD, El Nazir B, Taggart CC, Greene CM, McElvaney NG, Greally P. High concentrations of pepsin in bronchoalveolar lavage fluid from children with cystic fibrosis are associated with high interleukin-8 concentrations. Thorax. 2011;66(2):140-3.

14. Brodlie M, Aseeri A, Lordan JL, Robertson AG, McKean MC, Corris PA, Griffin SM, Manning NJ, Pearson JP, Ward C. Bile acid aspiration in people with cystic fibrosis before and after lung transplantation. Eur Respir J. 2015;46(6):1820-3.

15. Blondeau K, Dupont $L J$, Mertens V, Verleden G, Malfroot A, Vandenplas $Y$, Hauser B, Sifrim D. Gastro-oesophageal reflux and aspiration of gastric contents in adult patients with cystic fibrosis. Gut. 2008;57(8):1049-55.

\section{Submit your next manuscript to BioMed Central} and we will help you at every step:

- We accept pre-submission inquiries

- Our selector tool helps you to find the most relevant journal

- We provide round the clock customer support

- Convenient online submission

- Thorough peer review

- Inclusion in PubMed and all major indexing services

- Maximum visibility for your research

Submit your manuscript at www.biomedcentral.com/submit

) Biomed Central 